\title{
INFLUÊNCIA DA ALTERAÇÃO NOS TEMPOS DE CONDICIONAMENTO DE TRÊS SISTEMAS CERÂMICOS: UMA ANÁLISE VISUAL
}

Nancy Kudsi de CARVALHO; Luiz Felipe Gomes dos SANTOS; Renata dos Santos VIANNA; Antônio Fernando MONNERAT.

O estudo aborda o tratamento interno de estruturas cerâmicas de três sistemas: IPS Empress 2, IPS Empress Esthetic e cerâmica Felspática (Noritake); demonstra o aspecto das mesmas quando submetidas a condicionamento com ácido fluorídrico com adequado tempo de exposição, superexposição e subexposição, fornecendo parâmetros ao clínico para identificação das alterações e da condição ideal. Os três sistemas foram subdivididos em três grupos, contendo cada qual, 3 peças cerâmicas (uma unidade de cada sistema mencionado). Todas as amostras receberam condicionamento com ácido fluorídrico a 10\% (Cond Ac Porcelana $\left.{ }^{\circledR}, \mathrm{FGM}\right)$. No grupo I realizou-se subcondicionamento das peças; no grupo II realizou-se condicionamento pelo tempo adequado de acordo com os sistemas utilizados, e no grupo III supercondicionamento. Grupo I: IPS Empress Esthetic: 20 segundos; IPS Empress 2: 10 segundos; cerâmica Feldspática: 30 segundos; Grupo II: IPS Empress Esthetic: 1 minuto; IPS Empress 2: 30 segundos; cerâmica Feldspática:1 minuto e 30 segundos; Grupo III: IPS Empress Esthetic: 2 minutos e 30 segundos; IPS Empress 2: 1 minuto e 30 segundos; Cerâmica feldspática: 4 minutos. A visualização dos sinais clínicos de alteração do tempo de exposição ao ácido fluorídrico e respeitando o protocolo de uso do produto, obtém-se maior efetividade e longevidade da cimentação resinosa. 